\title{
The perceived risk of being infected with COVID-19 at work, communication, and employee health: A longitudinal applica- tion of the job demands-resources model
}

\author{
Alessandra Falco ${ }^{1}$, Damiano Girardi ${ }^{1}$, Alessandro De Carlo ${ }^{2}$, Elvira Arcucci ${ }^{1}$, and Laura Dal Corso ${ }^{1}$ \\ ${ }^{1}$ FISPPA Section of Applied Psychology, University of Padua, 35131 Padua, Italy \\ ${ }^{2}$ Department of Cardiac, Thoracic, Vascular Sciences and Public Health, University of Padua, 35128 Padua, \\ Italy
}

\begin{abstract}
The perceived risk of being infected at work (PRIW) with COVID-19 represents a potential risk factor for workers during the current COVID-19 pandemic. In line with the job demands-resources (JD-R) model applied to safety at work, in this longitudinal study we propose that PRIW can be conceptualized as a job demand, whereas communication (i.e., the exchange of good-quality information across team members) can be conceived as a job resource. Accordingly, we hypothesized that PRIW at Time 1 (T1) would positively predict psychophysical strain at Time 2 (i.e., four months later). Furthermore, we hypothesized that communication at T1 would negatively predict psychophysical strain at T2. Overall, 297 workers took part in the study. The hypothesized relationships were tested using multiple regression analysis. Results supported our predictions: PRIW positively predicted psychophysical strain over time, whereas communication negatively predicted psychophysical strain over time. Also, results did not change after controlling for age, gender, and type of contract. Overall, this study suggests that PRIW and communication can be considered as a risk and a protective factor for work-related stress, respectively. Hence, to promote more sustainable working conditions, interventions should encourage organizations to optimize the balance between job demands and job resources related to COVID-19.
\end{abstract}

Keywords: COVID-19; perceived risk; communication; psychophysical strain; longitudinal study.

\section{Introduction}

The current historical situation is characterized by the worldwide health emergency caused by COVID-19, an infectious disease that, starting from December 2019, has quickly taken the form of a pandemic. Since then, the COVID-19 outbreak has been affecting many areas of everyday life, including family, education, and work [13]. Regarding the work context, workers in many occupational sectors, in addition to healthcare professionals, are now facing the risk of being infected with COVID-19 at work [3], with the risks of major health (both physical and mental), social (e.g., social exclusion), and economic (e.g., financial loss) consequences [4]. Therefore, in the context of the current pandemic, safety at work - both physical and psychological - plays a central role in organizations, which need to be productive while preserving, at the same time, workers' psychophysical health and well-being [5]. Hence, to promote more sustainable working conditions aimed at fostering employees' health and wellbeing during the ongoing pandemic, work-related factors that may lead to both physical and psychological consequences related to COVID-19 risk (e.g., contracting COVID-19 and psychophysical symptoms associated to work-related stress, respectively) need to be thoroughly considered and addressed. In the light of this scenario, in this longitudinal study we investigated the association over time between two work-related factors linked to COVID-19 risk, namely the perceived risk of being infected at work (PRIW) with COVID-19 [6] and communication among team members [7-9], on the one hand, and psychophysical strain, in terms of psychophysical 
symptoms related to work-related stress (WRS), on the other [10,11]. More specifically, building on the Job Demands-Resources (JD-R) model [12,13] applied to safety at work [14-16], we conceptualized PRIW as a job demand (i.e., a risk factor for WRS), which may have negative consequences on employee's health and well-being over time. On the contrary, communication can be conceived as a job resource (i.e., a protective factor for WRS) that may help in preventing negative health consequences over time. We elaborate on these arguments in the following section.

\subsection{Job demands and resources related to safety at work}

According to the JD-R, job characteristics can be categorized either as job demands or job resources. Job demands are those aspects of a job (physical, psychological, social, or organizational) that require sustained physical and/or psychological (cognitive and emotional) effort from the worker and therefore are associated with certain physiological and/or psychological costs. Job resources refer to those aspects of a job (physical, psychological, social, or organizational) that are functional in achieving work objectives, reduce job demands and the associated costs (physiological and psychological), or promote personal growth, learning, and development $[12,13]$. Job demands and job resources respectively trigger two distinct processes: a health impairment process and a motivational process. In this study, we focused on the former. In the health impairment process, poorly designed jobs or chronic job demands require effort and drain employees' resources (mental and physical), which may lead to exhaustion and health complaints over time [13]. Furthermore, a lack of job resources precludes that job demands are met and that work goals are reached, which may result in job burnout and psychophysical symptoms over time [17-19].

Risk perception can be conceptualized as the "subjective assessment of the probability of a specified type of accident happening and how concerned we are with such an event" (p.152) [20], which implies a cognitive and an emotional or affective component of risk perception [21,22]. Recently, researchers around the world have focused on the perceived risk of COVID-19 infection, both in the general population [23,24] and among workers, including healthcare professionals [25-27] as well as workers from different occupational sectors $[6,28]$. The growing attention towards the risk of infection at work is consistent with the fact that workplaces and the organization of work have some features that may enhance the spread of SARS-CoV-2, such as, for example, physical proximity and frequent social interactions [29]. In line with the definition of job demand and the health impairment process, PRIW requires effort (e.g., to comply with safety procedures and/or to handle risky situations at work) and exhausts employees' mental and physical resources, such as time and energies, thus leading to the onset of psychophysical strain over time.

Communication is a central element of a good team work that refers to the exchange of good-quality (e.g., effective, clear and honest) information and feedbacks across team members (i.e., colleagues and supervisors) [6-9,30]. In this study we conceived communication as a job resource. Indeed, high-quality communication may play a motivational role by being functional in achieving work objectives, in terms of both safety outcomes and productivity [6]. Furthermore, good communication allows workers to complete tasks more effectively, thus fostering employees' perception of their competence [7]. Accordingly, communication can replenish personal resources like physical/psychological energies and capacities, thus contributing to prevent exhaustion and negative health consequences over time [31].

Empirical evidence, although still scant, supports the idea of an association between the perceived risk of infection at work and communication on the one hand (i.e., as a job demand and a job resource, respectively), and negative outcomes for the individual on the other. A recent research by Falco et al. [6] has shown that PRIW was positively associated with emotional exhaustion, a core component of job burnout [32], whereas communication was negatively associated with it. However, the study by Falco et al. employed a cross-sectional design, which did not inform about the direction of the 
associations. Hence, in the current research we addressed this limitation by using a longitudinal design. This allows us to investigate whether PRIW and communication at Time 1 (T1) are predictive of psychophysical strain at Time 2 (T2, that is, four months later), controlling for initial levels of psychophysical strain [33].

Overall, based on aforementioned arguments, the results of previous research, and given the assumptions of the JD-R model, we hypothesized that PRIW at T1 will positively predict psychophysical strain at T2. Specifically, higher levels of PRIW will be associated with higher levels of psychophysical strain four months later, controlling for initial levels of psychophysical strain.

Hypothesis 1: PRIW at T1 will positively predict psychophysical strain at T2.

Similarly, we hypothesized that communication at T1 will negatively predict psychophysical strain at T2. Specifically, higher levels of communication will be associated with lower levels of psychophysical strain four months later, controlling for initial levels of psychophysical strain.

Hypothesis 2: Communication at T1 will negatively predict psychophysical strain at T2.

Finally, it should be noted demographic characteristics such as gender and age, as well as work-related factors including the type of contract, may be associated with psychophysical strain. Regarding gender, previous studies in the organizational context showed that women tend to report higher levels of psychophysical strain [34-36]. A proposed explanation is that women may experience higher levels of work-family conflict [37] and lower levels of job resources (e.g., social support) [35], which in turn might result in higher levels of psychophysical strain [38]. Previous research has also shown age to be associated with psychophysical strain, albeit results have not been conclusive. For example, it is possible that a positive association between age and psychophysical strain exists $[39,40]$, given that symptoms take time to develop, so that elevated levels of psycho-physical strain reflect the cumulated effect of prolonged or chronic stress at the end of one's career [41,42]. Conversely, psychophysical strain may be negatively associated with age, possibly because older employees have higher levels of resilience or they develop coping skills with age or experience $[43,44]$. Interestingly, the relationship between age and psychophysical strain might differ across gender [42,45]. Finally, with respect to the type of contract, past research has shown an association between temporary employment and psychophysical strain, although with some differences across studies [46-49]. A possible explanation is that temporary employees may have unfavourable employment conditions (e.g., low wages, involuntary part-time), less job security and less participative decision making, which may have detrimental effects on workers' health [46,50,51]. Given the possible association between gender, age, and type of contract on the one hand, and psychphysical strain on the other, the hypotheses were tested both controlling for and not controlling for these demographic and work-related factors.

\section{Materials and Methods}

\subsection{Procedure and participants}

The study was carried out in a sample of workers from different organizations in Italy. Participants were approached by trained research assistants and were invited to complete an online questionnaire about their work experience between the end of October 2020 and the first half of November 2020 (i.e., T1). Participants were informed that they would be asked to complete a second questionnaire four months later (i.e., T2, between the end of February 2021 and the first half of March 2021). All participants were also informed of the overall purpose of the study, that participation was voluntary and confidential, and that they could withdraw from the research at any time. Upon acceptance, they were provided with a link that included the informed consent form and self report measures. All participants had to provide written informed consent before completing the questionnaire. The research project was approved by the Ethics Committee for the Psychological Research of the University of Padua, Italy (protocol n. 3842). The study also conformed to the Declaration of Helsinki (1964). Overall, 505 participants completed the 
questionnaire at T1, and 310 (61.4\%) completed the questionnaire at both $\mathrm{T} 1$ and $\mathrm{T} 2$. There were no differences in control (i.e., gender, age, and type of contract) or study variables between participants who did and did not complete the T2 questionnaire. Thirteen participants had missing values in at least one of the variables considered in the study. Data were missing completely at random (Little's missing completely at random test, $\chi^{2}=43.70$, $\mathrm{df}=37, p=0.21$ ), and cases with missing values on any of the measures considered in the study were removed from the dataset. Accordingly, the final sample comprised 297 participants. The sample consisted of 166 women (55.9\%) and 131 men (44.1\%) with a mean age of 36.9 years $(S D=12.3)$. Concerning the type of contract, 221 workers $(74.4 \%)$ had a permanent contract, whereas $76(25.6 \%)$ had a temporary contract. Regarding education, 168 workers $(56.6 \%)$ held a secondary degree, and 125 workers $(42.1 \%)$ had a university degree (4 missing values, $1.3 \%$ ). Finally, with respect to work experience, $48.5 \%$ had been with their current company for less than 5 years and $29.6 \%$ for more than 10 years (5 missing values, $1.7 \%$ ).

\subsection{Measures}

The following self-report measures were administered:

Psychophysical strain was assessed at T1 and T2 using a scale (14 items) taken from the $\mathrm{Q}_{\mathrm{u}}$-Bo test [52], an instrument standardized for the Italian context. Respondents were asked to indicate how often stress-related psychophysical symptoms had appeared or exacerbated over the past two months. Examples of scale items were "feeling tense and nervous" and "heartburn or pain in the stomach". The response scale ranged from 1 (never) to 6 (everyday). Cronbach's alpha for the overall scale was 0.92 at T1 and 0.94 at T2.

The perceived risk of being infected at work was measured at T1 using an adaptation of the CPRS [53] to the work context, that is, the CPRS-W [6]. The CPRS-W includes a cognitive dimension (e.g., "What is the likelihood that you would acquire the COVID-19 in your work organization?") and an emotional dimension [e.g., "How worried are you about a member of your work team (e.g., colleagues, supervisor) contracting the COVID19 in your work organization?"] of PRIW. The five-point response scale ranged from 1 (negligible) to 5 (very large), with higher scores indicating greater risk associated with COVID-19 in the work context. In line with the authors' suggestions [53] and previous validation [6], an overall score of perceived risk was computed. Cronbach's alpha for the overall scale was 0.90 .

Communication was assessed at T1 using a scale composed of 4 items taken from the $\mathrm{Q}_{\mathrm{u}-B o}$ test [52]. A sample item is "In my work group, communication is clear and timely". The response scale ranged from 1 (strongly disagree) to 6 (strongly agree). Cronbach's alpha for the overall scale was 0.91 .

\subsection{Data analysis}

The hypothesized relationships were tested using multiple regression analysis. Two different models were estimated. In model 1 (M1) psychophysical strain at T2 was the dependent variable, whereas psychophysical strain, PRIW, and communication at T1 were the independent variables. This model investigated whether PRIW and communication at $\mathrm{T} 1$ were predictive of psychophysical strain four months later, controlling for initial levels of psychophysical strain [33]. Model 2 (M2) was similar to M1, except that the relationships of interest were estimated after controlling for the effect of gender, age, and type of contract. To facilitate the interpretation of the results, the variables included in the models (with the exception of the dichotomous variables) have been centered [33,54]. Statistical analyses were carried out using the software R version 4.0.3 [R Core Team].

\section{Results}

Descriptive statistics and correlations between study variables are reported in Table 1. There was a positive, large-sized correlation between psychophysical strain at T1 and psychophysical strain at T2 $\left(\mathrm{r}_{295}=0.64, p<0.001\right)$. Furthermore, PRIW at T1 was positively associated with psychophysical strain at T2 $\left(\mathrm{r}_{295}=0.26, p<0.001\right)$, whereas communication 
at T1 was negatively associated with it $\left(\mathrm{r}_{295}=-0.27, p<0.001\right)$.

The results of the multiple regression analyses for M1 and M2 are presented in Table 2. In M2, the control variables at T1 were not associated with psychophysical strain at T2, and the results were very similar across the two models. Hence, the results of M1 (i.e., the more parsimonious model) are discussed [55,56]. Overall, the predictors at T1 accounted for over $40 \%$ of the variance in psychophysical strain at T2, $R^{2}=0.44, F(3,293)=75.52, p<$ 0.001. Psychophysical strain at T1 positively predicted psychophysical strain at T2, $b=$ $0.66, S E=0.05, p<0.001, \beta=0.59$, suggesting that strain is relatively stable across waves. Furthermore, PRIW at T1 positively predicted psychophysical strain at T2, $b=0.12, S E=$ $0.05, p<0.05, \beta=0.10$, whereas communication at T1 negatively predicted psychophysical strain at $\mathrm{T} 2, b=-0.08, S E=0.03, p<0.05, \beta=-0.10$. Hence, our hypotheses 1 and 2 were supported.

\subsection{Tables}

Table 1. Means, standard deviations, and correlations between study variables $(N=297)$.

\begin{tabular}{ccccccc}
\hline \multicolumn{1}{c}{ Variable } & $\boldsymbol{M}$ & SD & $\mathbf{1}$ & $\mathbf{2}$ & $\mathbf{3}$ & $\mathbf{4}$ \\
\hline 1. Psychophysical strain (T2) & 2.25 & 1.07 & - & & & \\
2. Psychophysical strain (T1) & 2.10 & 0.96 & $0.64^{* * *}$ & - & & \\
3. Perceived risk (T1) & 2.43 & 0.88 & $0.26^{* * *}$ & $0.25^{* * *}$ & - & \\
4. Communication (T1) & 3.51 & 1.42 & $-0.27^{* * *}$ & $-0.26^{* * *}$ & $-0.12^{*}$ & - \\
\hline
\end{tabular}

Note: T2 = Time 2; T1 = Time 1; Perceived risk = perceived risk of being infected at work. ${ }^{*} p<0.05 .{ }^{* * *} p<0.001$.

Table 2. Results from multiple regression analyses: Model 1 and Model $2(N=297)$.

\begin{tabular}{ccccc}
\hline Dependent variable: & \multicolumn{2}{c}{ Model 1 } & \multicolumn{2}{c}{ Model 2 } \\
\cline { 2 - 5 } psychophysical strain (T2) & $\boldsymbol{B}$ & $\mathrm{SE}$ & $\boldsymbol{B}$ & $\mathrm{SE}$ \\
\hline Intercept & $2.25^{* * *}$ & 0.05 & $2.29^{* * *}$ & 0.07 \\
Gender $^{1}$ & & & -0.13 & 0.10 \\
Age & & & 0.00 & 0.00 \\
Type of contract & & & 0.07 & 0.12 \\
Psychophysical strain (T1) & $0.66^{* * *}$ & 0.05 & $0.64^{* * *}$ & 0.05 \\
Perceived risk (T1) & $0.12^{*}$ & 0.05 & $0.12^{*}$ & 0.05 \\
Communication (T1) & $-0.08^{*}$ & 0.03 & $-0.08^{*}$ & 0.03 \\
\hline
\end{tabular}

Note: T2 = Time 2; T1 = Time 1; Perceived risk = perceived risk of being infected at work.

${ }^{1}$ Female $=0$, male $=1$.

${ }^{2}$ Permanent contract $=0$, temporary contract $=1$.

${ }^{*} p<0.05 .{ }^{* * *} p<0.001$.

\section{Discussion}

The ongoing outbreak of COVID-19 is a threat to global health and international economic [57], which has dramatically affected several areas of everyday life, including family, education, and work [1-3]. With respect to the latter, changes concerned the labor market (e.g., job loss and increasing unemployment) [58], work practices (e.g., remote work and virtual teamwork) [57], the accentuation of traditional risk factors (e.g., increased workload, job insecurity, and work-family conflict) as well as the emergence of new ones (e.g., social distancing and workplace loneliness) [57,59-62].

Not surprisingly, the perceived risk of infection at work has received growing attention worldwide, as the transmission of COVID-19 may occur in the workplace, and many jobs that were formerly considered as relatively safe are now seen as potentially dangerous [63]. In this longitudinal study, building on the JD-R [12,13] applied to safety at work [14-16], we conceptualized PRIW as a job demand which may have detrimental 
consequences on an employee's health and well-being over time. We also conceived communication as a job resource that may help in preventing negative health consequences over time. Accordingly, we hypothesized that PRIW at T1 would positively predict psychphysical strain at T2 (i.e., four months later), and that communication at T1 would negatively predict psychophysical strain at T2. Results largely supported our predictions. The perceived risk of COVID-19 infection positively predicted psychophysical strain over time, so that higher levels of PRIW were associated with higher levels of psychophysical strain four months later, controlling for initial levels of psychophysical strain. Similarly, communication negatively predicted psychophysical strain over time: higher levels of communication were associated with lower levels of psychophysical strain four months later, controlling for initial levels of psychophysical strain. Also, controlling for age, gender, and type of contract did not change these results.

Taken together, these results are consistent with the JD-R model, a flexible theoretical framework that has been applied to different work-related areas, such as work ability [64], career development [65], work-home interference [66], return to work after maternity leave [67] and, more recently, safety at work during the current outbreak of COVID-19 [6,27]. However, by using a longitudinal design, this study extends previous literature in this latter field - mostly based on cross-sectional findings - and suggests that PRIW and communication can be considered as a risk and a protective factor for WRS, respectively. Moreover, our results are consistent with previous studies on the relationship between PRIW and communication, on the one hand, and psychophysical symptoms related to WRS, on the other. With respect to PRIW, research carried out during different epidemics devoted considerable attention to healthcare workers (HCW), who are at a higher risk of infection than the general population [68], with considerable consequences in terms of stress and psycho-physical symptoms $[69,70]$. For example, past research conducted among healthcare professionals during the SARS epidemic showed that HCW perceived a great risk of personal exposure and fear of contracting the disease. They also reported increased work stress and workload and experienced significantly higher levels of anxiety [71,72]. Regarding the ongoing outbreak of COVID-19, several studies have shown that frontline HCW (i.e., who had experience in treating contaminated patients) perceived their workplace as more hazardous as well as characterized by higher risk of infection [70,71]. Furthermore, PRIW was associated with work-related stress and anxiety in response to COVID-19 among HCW [73]. Previous research, although still limited, also examined PRIW in the general working population (i.e., outside the healthcare context) [6,28,59]. For example, a recent study by Falco et al. [6] conducted on a sample of workers from different organizations in Italy, showed that PRIW - as a job demand - was positively associated with emotional exhaustion, a core component of job burnout [32], and that job resources related to COVID-19 (i.e., safety systems, communication, decisionmaking, and participation in decision-making) buffered this association, which was stronger for individuals with low levels of resources.

With respect to communication, previous research in the context of different pandemics has shown that adequate communication about the epidemic (e.g., sharing exact information about infection, a clear communication about guidelines and precautions) was associated with lower psychophysical strain among HCW [75]. For example, a study investigating the psychological impact of the H1N1 influenza pandemic in Japan showed that sharing correct information about infection is essential to contain the risk of stress among HCW [75]. Moreover, a clear communication about guidelines and precautions was also associated with fewer symptoms assessed by the General Health Questionnaire in a sample of hospital employees in Singapore during the SARS epidemic [76]. Furthermore, the study by Falco et al. [6], carried out in the general working population, has shown that communication concerning COVID-19 risk (i.e., the exchange of information, feedback, or possible reactions among team members) was negatively associated with emotional exhaustion. However, it should be noted that the current study, by adopting a longitudinal design, extends previous research, which was mostly based on cross-sectional data, and contributes to contextualize prior knowledge to the current 
COVID-19 outbreak. Of course, some limitations need to be acknowledged. First, the reversed effect of psychophysical strain on PRIW/communication over time was not considered in this study. It is possible that workers reporting higher levels of psychophysical strain may also perceive higher levels of risk and lower levels of communication over time, given their diminished resources (e.g., psychophysical energies) to handle risky situations at work or to promptly and effectively manage communications, respectively. Hence, albeit the associations hypothesized in this study are consistent with the JD-R model and previous empirical evidence [14-16,27,77,78], a future cross-lagged panel model could further investigate the reciprocal association over time between PRIW/communication and psychophysical strain. Second, in this study the focal constructs were determined using the same measurement method, that is, self-report questionnaires. Although the temporal separation between the measures of the predictor and criterion variables should reduce concerns about common method bias [79], future research could adopt observer-ratings of job demands and resources (e.g., supervisors' rating) or objective measures of psychophysical strain (e.g., biomarkers of stress) [80-84] to further support the validity of the proposed associations [85]. Finally, it should be noted that the longitudinal association between PRIW/communication and psychophysical strain was rather weak, and the predictors accounted for only a small proportion of variance in the dependent variable [86]. A possible explanation may relate to the time in which data collection occurred. Although the choice of a four-month time-lag is consistent with previous empirical studies and was based on the assumption that stressful situations, including work-related ones, may lose their impact on individuals' health and well-being if the time lag is too long [87-90], the two data collections overlap with two distinct phases of the pandemic in Italy: the "second wave" and the "third wave", respectively [91]. In this perspective, a weak association is understandable, given that PRIW/communication during the "second wave" may have a somewhat reduced salience in predicting psychophysical strain during the "third wave". Clearly, the evolution of a pandemic is unpredictable, but future studies could use shorter time lags to investigate in more detail the relationships over time between PRIW/communication and psychophysical strain.

Finally, we believe that our study has several practical implications for organizations and practitioners. More specifically, we suggest that effective interventions to reduce or manage PRIW should target both the organization and individuals, in terms of primary and secondary prevention, respectively. First, with respect to primary prevention, this study suggests that PRIW should be considered as an additional job demand for workers. Furthermore, past research has shown that job risks are associated with higher levels of workload for employees, who have to perform supplementary tasks to handle risky situations [77]. Hence, organizations should consider that workers have to invest additional psycho-physical energies in their work (e.g., to manage the risk of infection) and adjust working conditions accordingly, for example by providing employees with adequate time and resources (e.g., safety devices, spaces for social distancing, decision-making processes that prioritize safety at work) to achieve their work goals safely. Second, organizations should be encouraged to optimize the balance between job demands and job resources. In this perspective, organizations should encourage the exchange of good-quality information and feedback about COVID-19 risks among team members. This may help workers to achieve their work objectives safely and foster their perceived efficacy in managing the risk of infection. Finally, it should also be considered that PRIW can be reduced but likely cannot be completely eliminated. Hence, in terms of secondary prevention, interventions could help workers, especially those with high levels of personal demands, to manage more effectively the risk of COVID-19 infection. In the framework of the JD-R model, personal demands are those individual characteristics that compel individuals to invest exaggerated effort in their work and/or hinder employees' abilities to effectively cope with their work environment, thus being associated with psychological and/or physical costs [92]. For example, a study by Girardi et al. [93] has shown that the relationship between PRIW and psychophysical strain was stronger for individuals with high levels of negative affectivity (NA) - a dispositional 
dimension that reflects pervasive individual differences in negative emotionality and selfconcept [94] - probably because NA, as a personal demand, is related to reduced coping abilities [95]. At this level, organizations may then help workers with high levels of personal demands, including NA, to develop or strengthen the skills needed to cope effectively with the risk of infection at work, such as problem- and meaning-focused coping strategies [25].

\section{Conclusions}

In conclusion, this study showed that the perceived risk of being infected with COVID-19 at work, conceived as a job demand, positively predicted psychophysical strain four months later, whereas communication - as a job resource - negatively predicted psychophysical strain over time. All in all, our study emphasized the importance of a good balance between job demands (e.g., PRIW) and job resources (e.g., communication) related to COVID-19 to promote more sustainable working conditions, aimed at fostering employees' health and well-being during the ongoing pandemic.

Author Contributions: Conceptualization, A.F. and D.G.; Methodology, A.F., D.G. and L.D.C.; Validation, A.F. and A.D.C.; Formal Analysis, D.G.; Investigation, A.F. and D.G.; Resources, A.F., A.D.C. and L.D.C.; Writing - Original Draft Preparation, A.F., D.G., A.D.C. and E.A.; Writing - Review \& Editing, A.F., D.G., A.D.C., E.A. and L.D.C.; Visualization, E.A.; Supervision, A.F. All authors have read and agreed to the published version of the manuscript.

Funding: this research received no external funding

Data Availability Statement: the data presented in this study are available on reasonable request from the corresponding author. The data are not publicly available due to privacy reasons.

Conflicts of Interest: The authors declare no conflict of interest.

\section{References}

1. Daniel, S.J. Education and the COVID-19 Pandemic. Prospects 2020, 49, 91-96, doi:10.1007/s11125-020-09464-3.

2. Prime, H.; Wade, M.; Browne, D.T. Risk and Resilience in Family Well-Being during the COVID-19 Pandemic. Am Psychol. 2020, 75, 631-643, doi:10.1037/amp0000660.

3. Burdorf, A.; Porru, F.; Rugulies, R. The COVID-19 (Coronavirus) Pandemic: Consequences for Occupational Health. Scand J Work Environ Health 2020, 46, 229-230, doi:10.5271/sjweh.3893.

4. Hamouche, S. COVID-19 and Employees' Mental Health: Stressors, Moderators and Agenda for Organizational Actions. Emerald Open Res. 2020, 2, 15, doi:10.35241/emeraldopenres.13550.1.

5. Hu, X.; Yan, H.; Casey, T.; Wu, C.-H. Creating a Safe Haven during the Crisis: How Organizations Can Achieve Deep Compliance with COVID-19 Safety Measures in the Hospitality Industry. Int J Hosp Manag. 2021, 92, 102662, doi:10.1016/j.ijhm.2020.102662.

6. Falco, A.; Girardi, D.; Dal Corso, L.; Yıldırım, M.; Converso, D. The Perceived Risk of Being Infected at Work: An Application of the Job Demands-Resources Model to Workplace Safety during the COVID-19 Outbreak. PLoS ONE 2012, 16, e0257197, doi:10.1371/journal.pone.0257197.

7. Parker, S.K.; Axtell, C.M.; Turner, N. Designing a Safer Workplace: Importance of Job Autonomy, Communication Quality, and Supportive Supervisors. J Occup Health Psychol. 2001, 6, 211-228, doi:https://doi.apa.org/doi/10.1037/1076-8998.6.3.211.

8. Mariani, M.G.; Vignoli, M.; Chiesa, R.; Violante, F.S.; Guglielmi, D. Improving Safety through Non-Technical Skills in Chemical Plants: The Validity of a Questionnaire for the Self-Assessment of Workers. Int J Environ Res Public Health 2019, 16, 992, doi:10.3390/ijerph16060992. 
9. Converso, D.; Bruno, A.; Capone, V.; Colombo, L.; Falco, A.; Galanti, T.; Girardi, D.; Guidetti, G.; Viotti, S.; Loera, B. Working during a Pandemic between the Risk of Being Infected and/or the Risks Related to Social Distancing: First Validation of the SAPH@W Questionnaire. Int J Environ Res Public Health 2021, 18, 5986, doi:10.3390/ijerph18115986.

10. Nixon, A.E.; Mazzola, J.J.; Bauer, J.; Krueger, J.R.; Spector, P.E. Can Work Make You Sick? A Meta-Analysis of the Relationships between Job Stressors and Physical Symptoms. Work $\mathcal{E}$ Stress 2011, 25, 1-22, doi:10.1080/02678373.2011.569175.

11. Falco, A.; Girardi, D.; Marcuzzo, G.; De Carlo, A.; Bartolucci, G.B. Work Stress and Negative Affectivity: A MultiMethod Study. Occup Med. 2013, 63, 341-347, doi:10.1093/occmed/kqt054.

12. Demerouti, E.; Bakker, A.B.; Nachreiner, F.; Schaufeli, W.B. The Job Demands-Resources Model of Burnout. J Appl Psychol. 2001, 86, 499-512, doi:10.1037/0021-9010.86.3.499.

13. Bakker, A.B.; Demerouti, E. The Job Demands-Resources Model: State of the Art. J Manage Psychol. 2007, 22, 309328, doi:10.1108/02683940710733115.

14. Nahrgang, J.D.; Morgeson, F.P.; Hofmann, D.A. Safety at Work: A Meta-Analytic Investigation of the Link between Job Demands, Job Resources, Burnout, Engagement, and Safety Outcomes. J Appl Psychol. 2011, 96, 7194, doi:10.1037/a0021484.

15. Beus, J.M.; McCord, M.A.; Zohar, D. Workplace Safety: A Review and Research Synthesis. Organ Psychol Rev. 2016, 6, 352-381, doi:10.1177/2041386615626243.

16. Yaris, C.; Ditchburn, G.; Curtis, G.J.; Brook, L. Combining Physical and Psychosocial Safety: A Comprehensive Workplace Safety Model. Saf Sci 2020, 132, 104949, doi:10.1016/j.ssci.2020.104949.

17. Bakker, A.B.; Demerouti, E.; Verbeke, W. Using the Job Demands-Resources Model to Predict Burnout and Performance. Hum Resour Manage. 2004, 43, 83-104, doi:10.1002/hrm.20004.

18. Schaufeli, W.B.; Bakker, A.B. Job Demands, Job Resources, and Their Relationship with Burnout and Engagement: A Multi-Sample Study. J Organiz Behav 2004, 25, 293-315, doi:10.1002/job.248.

19. Dal Corso, L.; De Carlo, A.; Carluccio, F.; Colledani, D.; Falco, A. Employee Burnout and Positive Dimensions of Well-Being: A Latent Workplace Spirituality Profile Analysis. PLoS ONE 2020, 15, e0242267, doi:10.1371/journal.pone.0242267.

20. Marek, J; Tangernes, B; Hellesøy, OH Experience of Risk and Safety; Hellesøy OH: Oslo, 1985;

21. Rundmo, T. Safety Climate, Attitudes and Risk Perception in Norsk Hydro. Saf Sci 2000, 34, 47-59, doi:10.1016/S0925-7535(00)00006-0.

22. Rundmo, T.; Iversen, H. Risk Perception and Driving Behaviour among Adolescents in Two Norwegian Counties before and after a Traffic Safety Campaign. Saf Sci 2004, 42, 1-21, doi:10.1016/S0925-7535(02)00047-4.

23. Dryhurst, S.; Schneider, C.R.; Kerr, J.; Freeman, A.L.J.; Recchia, G.; van der Bles, A.M.; Spiegelhalter, D.; van der Linden, S. Risk Perceptions of COVID-19 around the World. J Risk Res. 2020, 23, 994-1006, doi:10.1080/13669877.2020.1758193.

24. Wise, T.; Zbozinek, T.D.; Michelini, G.; Hagan, C.C.; Mobbs, D. Changes in Risk Perception and Self-Reported Protective Behaviour during the First Week of the COVID-19 Pandemic in the United States. R Soc Open Sci. 2020, 7, 200742, doi:10.1098/rsos.200742.

25. Krok, D.; Zarzycka, B. Risk Perception of COVID-19, Meaning-Based Resources and Psychological Well-Being amongst Healthcare Personnel: The Mediating Role of Coping. J Clin Med. 2020, 9, 3225, doi:10.3390/jcm9103225.

26. Geng, S.; Zhou, Y.; Zhang, W.; Lou, A.; Cai, Y.; Xie, J.; Sun, J.; Zhou, W.; Liu, W.; Li, X. The Influence of Risk Perception for COVID-19 Pandemic on Posttraumatic Stress Disorder in Healthcare Workers: A Survey from Four Designated Hospitals. Clin Psychol Psychother. 2021, 2564, doi:10.1002/cpp.2564. 
27. Britt, T.W.; Shuffler, M.L.; Pegram, R.L.; Xoxakos, P.; Rosopa, P.J.; Hirsh, E.; Jackson, W. Job Demands and Resources among Healthcare Professionals during Virus Pandemics: A Review and Examination of Fluctuations in Mental Health Strain during COVID-19. Appl. Psychol. 2021, 70, 120-149, doi:10.1111/apps.12304.

28. Sinclair, R.R.; Probst, T.M.; Watson, G.P.; Bazzoli, A. Caught between Scylla and Charybdis: How Economic Stressors and Occupational Risk Factors Influence Workers' Occupational Health Reactions to COVID-19. Appl Psychol. 2021, 70, 85-119, doi:10.1111/apps.12301.

29. Lewandowski, P. Occupational Exposure to Contagion and the Spread of COVID-19 in Europe. IBS Working Paper 2020, 34 .

30. De Carlo, A.; Dal Corso, L.; Carluccio, F.; Colledani, D.; Falco, A. Positive Supervisor Behaviors and Employee Performance: The Serial Mediation of Workplace Spirituality and Work Engagement. Front. Psychol. 2020, 11, 1834, doi:10.3389/fpsyg.2020.01834.

31. Westman, M.; Hobfoll, S.E.; Chen, S.; Davidson, O.B.; Laski, S. Organizational stress Through the lens of conservation of resources (COR) theory. In Research in Occupational Stress and Well-being; Emerald (MCB UP ): Bingley, 2004; Vol. 4, pp. 167-220.

32. Taris, T.W.; Horn, J.E.V.; Schaufeli, W.B.; Schreurs, P.J.G. Inequity, Burnout and Psychological Withdrawal among Teachers: A Dynamic Exchange Model. Anxiety, Stress \& Coping 2004, 17, 103-122, doi:10.1080/1061580031000151620.

33. Newsom, J.T. Longitudinal Structural Equation Modeling: A Comprehensive Introduction; 1st ed.; Routledge: New York, 2015;

34. Giorgi, G.; Perez, J.M.L.; D’Antonio, A.C.; Perez, F.J.F.; Arcangeli, G.; Cupelli, V.; Mucci, N. The General Health Questionaire (GHQ-12) in a Sample of Italian Workers: Mental Health at Individual and Organizational Level. World J Medical Sci. 2014, 11, 47-56, doi:10.5829/idosi.wjms.2014.11.1.83295.

35. Väänänen, A.; Toppinen-Tanner, S.; Kalimo, R.; Mutanen, P.; Vahtera, J.; Peiró, J.M. Job Characteristics, Physical and Psychological Symptoms, and Social Support as Antecedents of Sickness Absence among Men and Women in the Private Industrial Sector. Soc Sci Med. 2003, 57, 807-824, doi:10.1016/S0277-9536(02)00450-1.

36. Viertiö, S. Factors Contributing to Psychological Distress in the Working Population, with a Special Reference to Gender Difference. BMC Public Health volume 2021, 21, doi:https://doi.org/10.1186/s12889-021-10560-y.

37. Innstrand, S.T.; Langballe, E.M.; Falkum, E.; Aasland, O.G. Exploring Within- and between-Gender Differences in Burnout: 8 Different Occupational Groups. Int Arch Occup Environ Health 2011, 84, 813-824, doi:10.1007/s00420011-0667-y.

38. Amstad, F.T.; Meier, L.L.; Fasel, U.; Elfering, A.; Semmer, N.K. A Meta-Analysis of Work-Family Conflict and Various Outcomes with a Special Emphasis on Cross-Domain versus Matching-Domain Relations. J Occup Health Psychol. 2011, 16, 151-169, doi:10.1037/a0022170.

39. Vanagas, G.; Bihari-Axelsson, S.; Vanagiene, V. Do Age, Gender and Marital Status Influence Job Strain Development for General Practitioner? Medicina (Kaunas) 2004, 40.

40. Cassou, B. Chronic Neck and Shoulder Pain, Age, and Working Conditions: Longitudinal Results from a Large Random Sample in France. Occup Environ Med. 2002, 59, 537-544, doi:10.1136/oem.59.8.537.

41. Ganster, D.C.; Rosen, C.C. Work Stress and Employee Health: A Multidisciplinary Review. J Manage. 2013, 39, 1085-1122, doi:10.1177/0149206313475815.

42. Ahola, K.; Honkonen, T.; Virtanen, M.; Aromaa, A.; Lönnqvist, J. Burnout in Relation to Age in the Adult Working Population. Jrnl of Occup Health 2008, 50, 362-365, doi:10.1539/joh.M8002.

43. Hybels, C.F.; Blazer, D.G.; Eagle, D.E.; Proeschold-Bell, R.J. Age Differences in Trajectories of Depressive, Anxiety, and Burnout Symptoms in a Population with a High Likelihood of Persistent Occupational Distress. Int Psychogeriatr. 2020, 1-12, doi:10.1017/S1041610220001751. 
44. Brewer, E.W.; Shapard, L. Employee Burnout: A Meta-Analysis of the Relationship Between Age or Years of Experience. Hum Resour Dev Rev. 2004, 3, 102-123, doi:10.1177/1534484304263335.

45. Sanchez-Lopez, P.; Saavedra-San Roman, A.I.; Dresch, V.; Garcia-Quintans, L.; Rodrigo-Holgado, I. Women Are More at Risk of Poor Mental Health: Mental Health of Spanish Nurses Measured by the GHQ-12. Women's Health Bull. 2016, 3, doi:10.17795/whb-29603.

46. Virtanen, M.; Kivimäki, M.; Joensuu, M.; Virtanen, P.; Elovainio, M.; Vahtera, J. Temporary Employment and Health: A Review. Int J Epidemiol. 2005, 34, 610-622, doi:10.1093/ije/dyi024.

47. Waenerlund, A.-K.; Virtanen, P.; Hammarström, A. Is Temporary Employment Related to Health Status? Analysis of the Northern Swedish Cohort. Scand J Public Health 2011, 39, 533-539, doi:10.1177/1403494810395821.

48. Benavides, F.G. How Do Types of Employment Relate to Health Indicators? Findings from the Second European Survey on Working Conditions. J Epidemiol Community Health 2000, 54, 494-501, doi:10.1136/jech.54.7.494.

49. Bardasi, E.; Francesconi, M. The Impact of Atypical Employment on Individual Wellbeing: Evidence from a Panel of British Workers. Soc Sci Med. 2004, 58, 1671-1688, doi:10.1016/S0277-9536(03)00400-3.

50. Gundert, S.; Hohendanner, C. Do Fixed-Term and Temporary Agency Workers Feel Socially Excluded? Labour Market Integration and Social Well-Being in Germany. Acta Sociol. 2014, 57, 135-152, doi:10.1177/0001699313496588.

51. Lee, W.-W.; Park, J.-B.; Min, K.-B.; Lee, K.-J.; Kim, M.-S. Association between Work-Related Health Problems and Job Insecurity in Permanent and Temporary Employees. Ann of Occup and Environ Med 2013, 25, 15, doi:10.1186/2052-4374-25-15.

52. De Carlo, N.A.; Falco, A.; Capozza, D. Test Di Valutazione Del Rischio Stress Lavoro-Correlato Nella Prospettiva Del Benessere Organizzativo, Qu-Bo; FrancoAngeli: Milano, 2008;

53. Yıldırım, M.; Güler, A. Factor Analysis of the COVID-19 Perceived Risk Scale: A Preliminary Study. Death Stud. 2020, 1-8, doi:10.1080/07481187.2020.1784311.

54. Dawson, J.F. Moderation in Management Research: What, Why, When, and How. J Bus Psychol. 2014, 29, 1-19, doi:10.1007/s10869-013-9308-7.

55. Becker, T.E.; Atinc, G.; Breaugh, J.A.; Carlson, K.D.; Edwards, J.R.; Spector, P.E. Statistical Control in Correlational Studies: 10 Essential Recommendations for Organizational Researchers. J Organiz Behav. 2016, 37, 157-167, doi:10.1002/job.2053.

56. Bernerth, J.B.; Aguinis, H. A Critical Review and Best-Practice Recommendations for Control Variable Usage. Pers Psychol. 2016, 69, 229-283, doi:10.1111/peps.12103.

57. Kniffin, K.M.; Narayanan, J.; Anseel, F.; Antonakis, J.; Ashford, S.P.; Bakker, A.B.; Bamberger, P.; Bapuji, H.; Bhave, D.P.; Choi, V.K.; et al. COVID-19 and the Workplace: Implications, Issues, and Insights for Future Research and Action. Am Psychol. 2021, 76, 63-77, doi:10.1037/amp0000716.

58. ILO Monitor: COVID-19 and the World of Work. 7th Edition; International Labour Organization (ILO): Geneva, Switzerland, 2021;

59. Bellotti, L.; Zaniboni, S.; Balducci, C.; Grote, G. Rapid Review on COVID-19, Work-Related Aspects, and Age Differences. IJERPH 2021, 18, 5166, doi:10.3390/ijerph18105166.

60. Kinman, G.; Grant, C. Presenteeism during the COVID-19 Pandemic: Risks and Solutions. Occup Med. 2021, 71, 243-244, doi:10.1093/occmed/kqaa193.

61. Sadiq, M. Policing in Pandemic: Is Perception of Workload Causing Work-Family Conflict, Job Dissatisfaction and Job Stress? J Public Affairs. 2020, e2486, doi:10.1002/pa.2486.

62. Carnevale, J.B.; Hatak, I. Employee Adjustment and Well-Being in the Era of COVID-19: Implications for Human Resource Management. J Bus Res. 2020, 116, 183-187, doi:10.1016/j.jbusres.2020.05.037. 
63. Sinclair, R.R.; Probst, T.M.; Watson, G.P.; Bazzoli, A. Caught between Scylla and Charybdis: How Economic Stressors and Occupational Risk Factors Influence Workers' Occupational Health Reactions to COVID-19. Appl Psychol. 2021, 70, 85-119, doi:10.1111/apps.12301.

64. Viotti, S.; Guidetti, G.; Loera, B.; Martini, M.; Sottimano, I.; Converso, D. Stress, Work Ability, and an Aging Workforce: A Study among Women Aged 50 and Over. Int J Stress Manag. 2017, 24, 98-121, doi:10.1037/str0000031.

65. Lee, Y.; Eissenstat, S.J. An Application of Work Engagement in the Job Demands-Resources Model to Career Development: Assessing Gender Differences. Human Resource Dev Quarterly 2018, 29, 143-161, doi:10.1002/hrdq.21310.

66. De Carlo, A.; Girardi, D.; Falco, A.; Dal Corso, L.; Di Sipio, A. When Does Work Interfere With Teachers' Private Life? An Application of the Job Demands-Resources Model. Front Psychol. 2019, 10, 1121, doi:10.3389/fpsyg.2019.01121.

67. Carluccio, F.; Dal Corso, L.; Falco, A.; De Carlo, A. How to Positively Manage Return to Work after Maternity Leave: Positive Supervisor Behaviors to Promote Working Mothers' Well-Being. TPM 2020, 27, 583-601, doi:10.4473/TPM27.4.6.

68. Koh, D. Occupational Risks for COVID-19 Infection. Occup Med. 2020, 70, 3-5, doi:10.1093/occmed/kqaa036.

69. Du, J.; Dong, L.; Wang, T.; Yuan, C.; Fu, R.; Zhang, L.; Liu, B.; Zhang, M.; Yin, Y.; Qin, J.; et al. Psychological Symptoms among Frontline Healthcare Workers during COVID-19 Outbreak in Wuhan. Gen Hosp Psychiatry 2020, 67, 144-145, doi:10.1016/j.genhosppsych.2020.03.011.

70. Chew, N.W.S.; Lee, G.K.H.; Tan, B.Y.Q.; Jing, M.; Goh, Y.; Ngiam, N.J.H.; Yeo, L.L.L.; Ahmad, A.; Ahmed Khan, F.; Napolean Shanmugam, G.; et al. A Multinational, Multicentre Study on the Psychological Outcomes and Associated Physical Symptoms amongst Healthcare Workers during COVID-19 Outbreak. Brain Behav Immun. 2020, 88, 559-565, doi:10.1016/j.bbi.2020.04.049.

71. Chong, M.-Y.; Wang, W.-C.; Hsieh, W.-C.; Lee, C.-Y.; Chiu, N.-M.; Yeh, W.-C.; Huang, T.-L.; Wen, J.-K.; Chen, C.L. Psychological Impact of Severe Acute Respiratory Syndrome on Health Workers in a Tertiary Hospital. Br J Psychiatry 2004, 185, 127-133, doi:10.1192/bjp.185.2.127.

72. Koh, D.; Lim, M.K.; Chia, S.E.; Ko, S.M.; Qian, F.; Ng, V.; Tan, B.H.; Wong, K.S.; Chew, W.M.; Tang, H.K.; et al. Risk Perception and Impact of Severe Acute Respiratory Syndrome (SARS) on Work and Personal Lives of Healthcare Workers in Singapore: What Can We Learn? Med Care 2005, 43, 676-682, doi:10.1097/01.mlr.0000167181.36730.cc.

73. Lee, J.; Lee, H.J.; Hong, Y.; Shin, Y.-W.; Chung, S.; Park, J. Risk Perception, Unhealthy Behavior, and Anxiety Due to Viral Epidemic Among Healthcare Workers: The Relationships With Depressive and Insomnia Symptoms During COVID-19. Front Psychiatry 2021, 12, 615387, doi:10.3389/fpsyt.2021.615387.

74. Gorini, A.; Fiabane, E.; Sommaruga, M.; Barbieri, S.; Sottotetti, F.; La Rovere, M.T.; Tremoli, E.; Gabanelli, P. Mental Health and Risk Perception among Italian Healthcare Workers during the Second Month of the Covid-19 Pandemic. Arch Psychiatr Nurs. 2020, 34, 537-544, doi:10.1016/j.apnu.2020.10.007.

75. Matsuishi, K.; Kawazoe, A.; Imai, H.; Ito, A.; Mouri, K.; Kitamura, N.; Miyake, K.; Mino, K.; Isobe, M.; Takamiya, S.; et al. Psychological Impact of the Pandemic (H1N1) 2009 on General Hospital Workers in Kobe: Pandemic in Kobe. Psychiatry Clin Neurosci 2012, 66, 353-360, doi:10.1111/j.1440-1819.2012.02336.x.

76. Chan, A.O.M. Psychological Impact of the 2003 Severe Acute Respiratory Syndrome Outbreak on Health Care Workers in a Medium Size Regional General Hospital in Singapore. Occ Med. 2004, 54, 190-196, doi:10.1093/occmed/kqh027.

77. Leiter, M.P. Perception of Risk: An Organizational Model of Occupational Risk, Burnout, and Physical Symptoms. Anxiety, Stress \& Coping 2005, 18, 131-144, doi:10.1080/10615800500082473. 
78. Day, A.L.; Sibley, A.; Scott, N.; Tallon, J.M.; Ackroyd-Stolarz, S. Workplace Risks and Stressors as Predictors of Burnout: The Moderating Impact of Job Control and Team Efficacy. Can j Adm Sci 2009, 26, 7-22, doi:10.1002/cjas.91.

79. Podsakoff, P.M.; MacKenzie, S.B.; Podsakoff, N.P. Sources of Method Bias in Social Science Research and Recommendations on How to Control It. Annu Rev Psychol. 2012, 63, 539-569, doi:10.1146/annurev-psych-120710100452.

80. Falco, A.; Dal Corso, L.; Girardi, D.; De Carlo, A.; Comar, M. The Moderating Role of Job Resources in the Relationship between Job Demands and Interleukin-6 in an Italian Healthcare Organization. Res Nurs Health 2018, 41, 39-48, doi:10.1002/nur.21844.

81. Penz, M.; Siegrist, J.; Wekenborg, M.K.; Rothe, N.; Walther, A.; Kirschbaum, C. Effort-Reward Imbalance at Work Is Associated with Hair Cortisol Concentrations: Prospective Evidence from the Dresden Burnout Study. Psychoneuroendocrinology 2019, 109, 104399, doi:10.1016/j.psyneuen.2019.104399.

82. Falco, A.; Girardi, D.; Parmiani, G.; Bortolato, S.; Piccirelli, A.; Bartolucci, G.B.; De Carlo, N.A. Presenteeism and Workers' Health: Effects of Mediation on Psycho-Physical Stress in a Longitudinal Study. G Ital Med Lav Ergon. 2013, 35, 138-150.

83. Falco, A.; Girardi, D.; Sarto, F.; Marcuzzo, G.; Vianello, L.; Magosso, D.; Dal Corso, L.; Bartolucci, G.B.; De Carlo, N.A. A New Scale for Measuring the Psycho-Physical Effects of Work-Related Stress in a Perspective of Methods Integration. Med Lav. 2012, 103, 288-308.

84. Falco, A.; Girardi, D.; Kravina, L.; De Carlo, N.A. The Convergence between Self and Observer Ratings of Workaholism: A Comparison between Couples. TPM 2012, 311-324, doi:10.4473/TPM19.4.5.

85. Griffin, M.A. Dispositions and Work Reactions: A Multilevel Approach. J Appl Psychol. 2001, 86, 1142-1151, doi:10.1037/0021-9010.86.6.1142.

86. Cohen, J. A Power Primer. Psychol Bull 1992, 112, 155-159, doi:10.1037/0033-2909.112.1.155.

87. Dormann, C.; Griffin, M.A. Optimal Time Lags in Panel Studies. Psychol Methods 2015, 20, 489-505, doi:10.1037/met0000041.

88. Diener, E. Subjective Well-Being: The Science of Happiness and a Proposal for a National Index. Am Psychol 2000, 55, 34-43, doi:10.1037/0003-066X.55.1.34.

89. Zapf, D.; Dormann, C.; Frese, M. Longitudinal Studies in Organizational Stress Research: A Review of the Literature with Reference to Methodological Issues. J Occup Health Psychol. 1996, 1, 145-169, doi:10.1037/10768998.1.2.145.

90. Britt, T.W.; Dawson, C.R. Predicting Work-Family Conflict from Workload, Job Attitudes, Group Attributes, and Health: A Longitudinal Study. Mil Psychol. 2005, 17, 203-227, doi:10.1207/s15327876mp1703_5.

91. Davoli, M.; de' Donato, F.; De Sario, M.; Di Blasi, C.; Michelozzi, P.; Noccioli, F.; Orrù, D.; Rossi, P. Andamento Della Mortalità Giornaliera (SiSMG) Nelle Città Italiane in Relazione All'epidemia Di Covid-19. Rapporto 1 Settembre 2020 - 29 Giugno 2021; Ministero della Salute: Roma, IT, 2021;

92. Zeijen, M.E.L.; Brenninkmeijer, V.; Peeters, M.C.W.; Mastenbroek, N.J.J.M. Exploring the Role of Personal Demands in the Health-Impairment Process of the Job Demands-Resources Model: A Study among Master Students. IJERPH 2021, 18, 632, doi:10.3390/ijerph18020632.

93. Girardi, D.; De Carlo, A.; Dal Corso, L.; Di Sipio, A.; Falco, A. Risk of COVID-19 Infection at Work and PsychoPhysical Strain: The Moderating Role of Negative Affectivity. In Proceedings of the Psychological Applications and Trends 2021; Pracana, C., Wang, M., Eds.; inScience Press: Lisboa, Portugal, 2021; pp. 312-316.

94. Watson, D.; Clark, L.A. Negative Affectivity: The Disposition to Experience Aversive Emotional States. Psychol Bull. 1984, 96, 465-490, doi:10.1037/0033-2909.96.3.465.

95. Hofmann, H.; Kohlmann, C.-W. The Role of Positive and Negative Affectivity in Healthy and Unhealthy WorkRelated Behavior and Experiences. Eur J Health Psychol. 2019, 26, 56-67, doi:10.1027/2512-8442/a000030. 